\title{
INFLUENCE OF GRAPHENE OXIDES PRODUCED BY DIFFERENT PROCESSING TECHNIQUES ON THE CORROSION RESISTANCE OF ELECTRODEPOSITED Zn-GRAPHENE COMPOSITE COATINGS
}

\author{
Nicoleta COTOLAN, ${ }^{\mathrm{a}}$ Liviu Cosmin COTET, ${ }^{\mathrm{a}}$ Daniel MARCONI ${ }^{\mathrm{b}}$ and Liana Maria MURESAN ${ }^{\mathrm{a}, *}$ \\ a Department of Chemical Engineering, Faculty of Chemistry and Chemical Engineering, "Babes-Bolyai" University, \\ 11 Arany Janos Street, 400028 Cluj-Napoca, Roumania \\ ${ }^{\mathrm{b}}$ Department of Molecular and Biomolecular Physics, National Institute for Research and Development of Isotopic \\ and Molecular Technologies, 67-103 Donath Street, 400293 Cluj-Napoca, Roumania
}

The present work is focused on the characterization of new composite zinc electrodeposits containing several graphene oxides produced by different processing techniques, aiming to improve the corrosion resistance of steel substrates. The corrosion behavior of the zinc-graphene composite deposits obtained from an acidic electrolyte $(\mathrm{pH}=5.6)$ at two current densities $\left(20 \mathrm{~mA} / \mathrm{cm}^{2}\right.$ and $\left.40 \mathrm{~mA} / \mathrm{cm}^{2}\right)$ in the presence of several types of graphene oxides produced by graphite exfoliation was investigated. Electrochemical impedance spectroscopy (EIS) and potentiodynamic polarization methods were used to characterize the corrosion behavior of the deposits. The obtained results for $\mathrm{Zn} / \mathrm{steel}$, and $\mathrm{Zn}$-graphene/steel deposits were compared in the same experimental conditions. The incorporation of graphene oxide in zinc matrices enhanced the corrosion resistance of the resulting composite coatings when compared to pure zinc coating and the degree of enhancement depends on the graphene oxide nature and preparation mode.

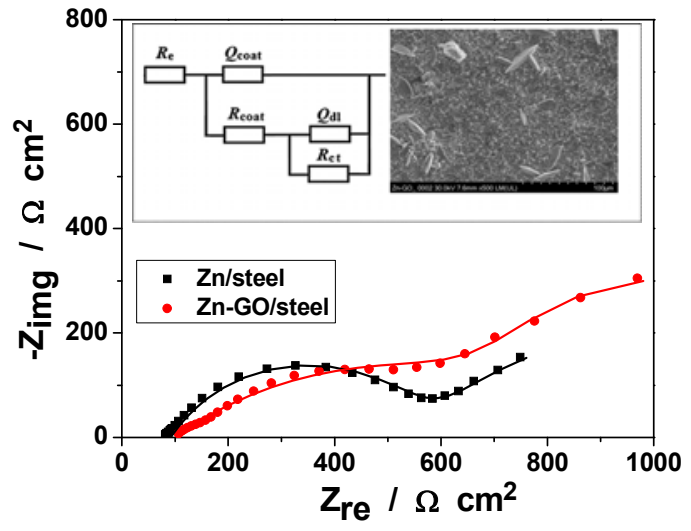

\section{INTRODUCTION}

Zinc is widely used as sacrificial coating on mild steel, however its lifespan is limited in aggressive environments. ${ }^{1} \quad \mathrm{Zn}$-based protective coatings are preferred over Ni-based coatings as the formation of nano/micro defects in Ni plating can lead to the corrosion of underlying steel substrates due to galvanic cell formation in which Ni plays the role of cathode.

There are several ways to improve the corrosion resistance of zinc-coated steel, varying from chromating the zinc surface ${ }^{2-4}$ to its coating with organic molecules ${ }^{5}$ and to incorporation of useful nanoparticles in the zinc coating.,

\footnotetext{
*Corresponding author: limur@chem.ubbcluj.ro
}

Zinc-nanoparticles composite coatings are meant to provide better corrosion resistance to steel than pure zinc due to the fact that the nanoparticles confer to the composite layers improved corrosion and wear resistance, increased hardness, better adhesion of future paint layers, and prolonged lifetime. ${ }^{8}$ Various nanoparticles such as $\mathrm{TiO}_{2},{ }^{9-12} \mathrm{SiO}_{2},{ }^{13,14} \mathrm{Al}_{2} \mathrm{O}_{3},{ }^{15,16}$ $\mathrm{CeO}_{2},{ }^{17}$ mixed oxides ${ }^{18,19}$ and carbon fibers, ${ }^{20}$ and other were used for enhancing the corrosion resistance of zinc coatings.

Recently, graphene materials have attracted considerable attention due to their valuable characteristics such as high electrical and thermal conductivity, excellent mechanical properties and large surface area. ${ }^{21,22}$ Graphene oxide incorporated 
in polymers, ${ }^{23}$ deposited on metallic surfaces, ${ }^{24}$ dispersed in the corrosive media ${ }^{25}$ or used to reinforce metallic coatings ${ }^{26-28}$ represents an attractive alternative to improve corrosion resistance of metals.

Zn-graphene composite coatings on steel were prepared by electrodeposition ${ }^{29}$ and reported as significantly better corrosion resistant than pure zinc. Incorporation of graphene materials into the zinc matrix hindered the formation of pits on the surface and favored the formation of hillock structures. However, no correlation between the graphene material origin or preparation method and the corrosion properties of the resulting coatings was reported.

In this context, this work investigates the effect of graphene oxide with different oxidation degree and of some experimental conditions on the corrosion behavior of $\mathrm{Zn}$-graphene composite coatings. More specifically, the coatings were electrodeposited on carbon steel from an acidic electrolytic bath using four types of graphene oxides produced by graphite sono-chemical exfoliation $^{30}$ and a commercially available reduced graphene oxide, respectively, and the electrochemical behavior of the coatings were corroborated with the characteristics of graphene materials.

\section{RESULTS AND DISCUSSION}

\section{Morpho-structural investigations}

Figure 1 shows the SEM images of $\mathrm{Zn} /$ steel (A), Zn-rGO/steel (B) and Zn-GO/steel (C) deposits.

The surface morphology is different in the three cases. The pure $\mathrm{Zn}$ coating contains vertical platelets, while the $\mathrm{Zn}-\mathrm{rGO} /$ steel deposit contains irregular nodules distributed on the whole electrode surface. On the contrary, Zn-GO/steel deposits are more uniform and fine grained, suggesting a higher rate of deposition associated with a better interaction of GO with the $\mathrm{Zn}$ matrix.

These results are confirmed by EDS analysis (Table 1). It can be observed that the highest $\mathrm{C}$ content was recorded in the case of $\mathrm{Zn}-\mathrm{GO} /$ steel deposits, which is expected, suggesting that the incorporation degree of $\mathrm{GO}$ is higher during the simultaneous electroreduction of $\mathrm{Zn}^{2+}$ ions and GO suspension than in the case of already reduced graphene (rGO).

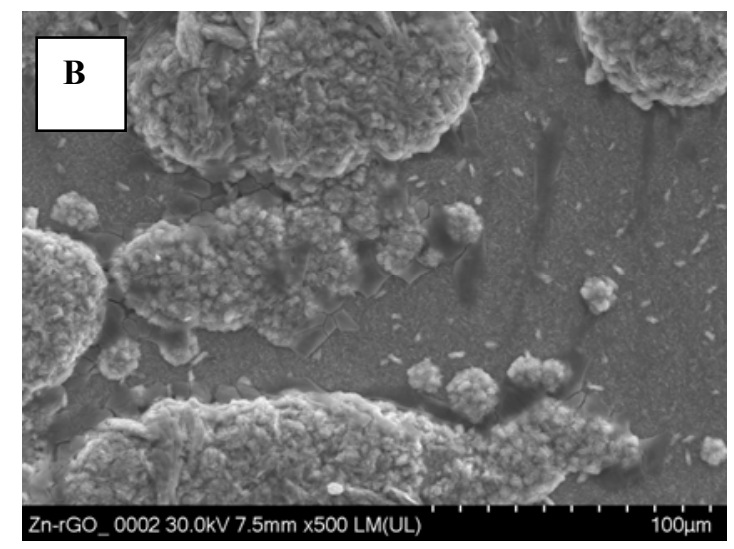

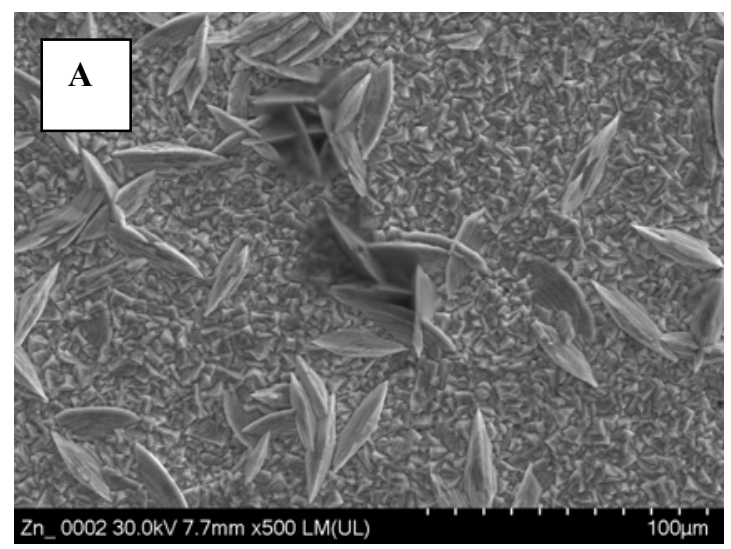

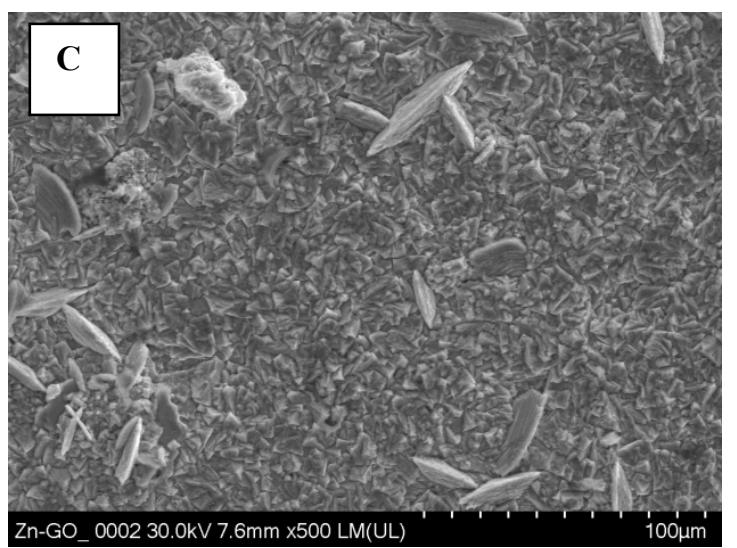

Fig. 1 - SEM micrographs of Zn/steel (A), Zn-rGO/steel (B) and Zn-GO/steel (C). 
Table 1

Deposits composition determined by EDS measurements

\begin{tabular}{c|c|c|c}
\hline \multirow{2}{*}{ Sample } & \multicolumn{3}{|c}{ Element content (weight \%) } \\
\cline { 2 - 4 } & Zn/steel & Zn-GO/steel & Zn-rGO/steel \\
\hline $\mathbf{C}$ & 6 & 19 & 4 \\
$\mathbf{S}$ & 3 & 6 & 22 \\
$\mathbf{C l}$ & - & - & 4 \\
$\mathbf{N a}$ & - & - & 2 \\
$\mathbf{F e}$ & - & - & 9 \\
$\mathbf{Z n}$ & - & - & 11 \\
Total & 91 & 75 & 48 \\
\hline
\end{tabular}

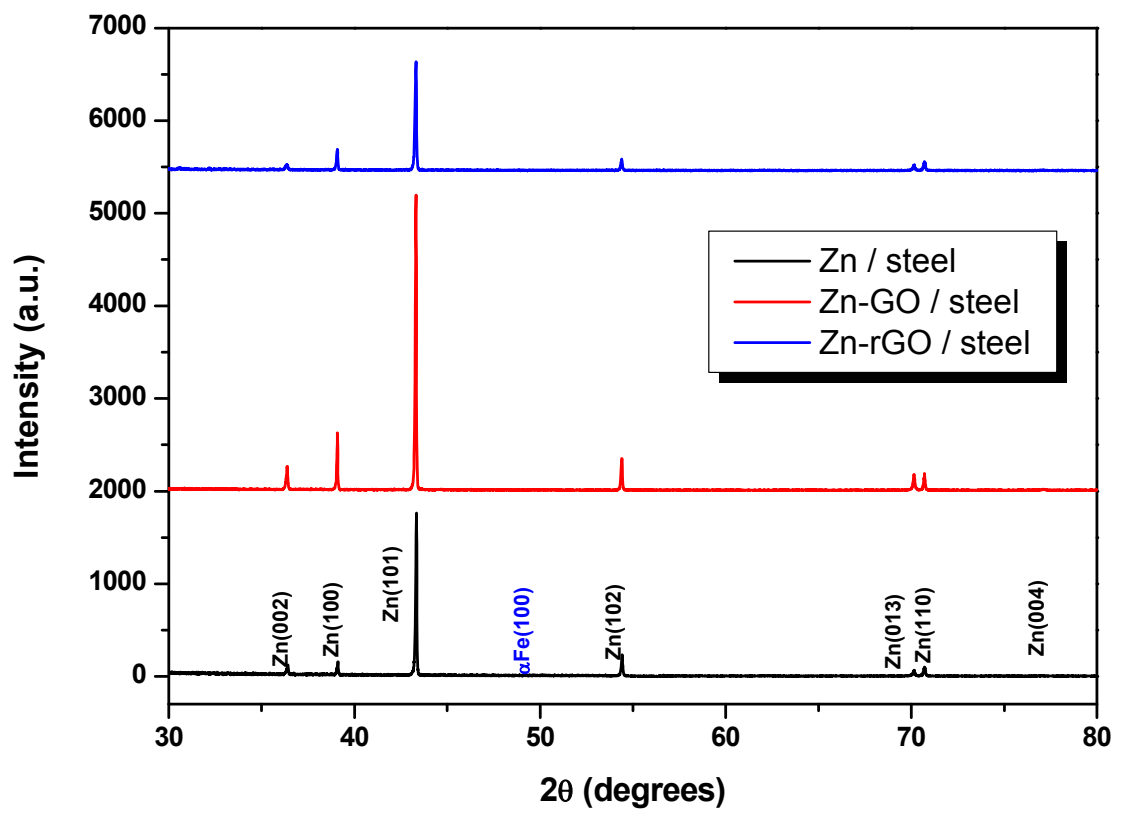

Fig. 2 - XRD spectra of Zn/steel, Zn-GO/steel and Zn-rGO/steel.

The XRD spectra of the three deposits are depicted in Figure 2. It can be observed that the texture of the deposits is not the same in all cases and that the presence of incorporated graphene material changed the microstructure of the coating. Thus, the electrochemically reduced GO incorporated in the deposit enhances the crystal growth along (101) and (100) low index crystallographic planes. These results are in agreement with those reported in the literature. ${ }^{29}$

\section{Polarization curves}

Tafel polarization curves of $\mathrm{Zn}, \mathrm{Zn}-\mathrm{rGO}$ and $\mathrm{Zn}-\mathrm{GO}$ coatings were recorded in the potential range of $\pm 250 \mathrm{mV}$ against the open circuit potential of the respective coating which was used as working electrode and are presented in Figure 3.

For the composite coatings obtained with the three different $\mathrm{GO}$ fractions $\mathrm{SF}, \mathrm{OF}$ and $\mathrm{PF}$ prepared by centrifugation of the initial GO suspension, the potentiodynamic curves are presented in Figure 4. For all the coatings, the results extracted by the interpretation of the polarization curves by Tafel method are presented in Table 2.

The corrosion current density for the $\mathrm{Zn}$-rGO and $\mathrm{Zn}-\mathrm{GO}$ coated samples is generally lower than that of their $\mathrm{Zn}$ coated counterparts. This could be associated to an increase of corrosion resistance of the composite coatings as a consequence of the inclusion of GO in the metallic deposit. A possible explanation could be the change and refining of the zinc deposit microstructure in the presence of graphene materials, as observed also by other authors $^{29}$ and put in evidence by the beforepresented morpho-structural results. The better behavior of the deposits prepared by electrochemical reduction of GO in comparison with those prepared with $\mathrm{rGO}$ could be due to the more uniform distribution of the graphene material resulted by simultaneous reduction of GO and $\mathrm{Zn}^{2+}$ ions inside the zinc matrix than in the case when commercial rGO was used. The better solubility of $\mathrm{GO}$ in the plating electrolyte plays also a positive 
role. It should be mentioned that the presence of reduced GO influences both the anodic and cathodic branches of the polarization curves, suggesting that on one side, the coating acts as a
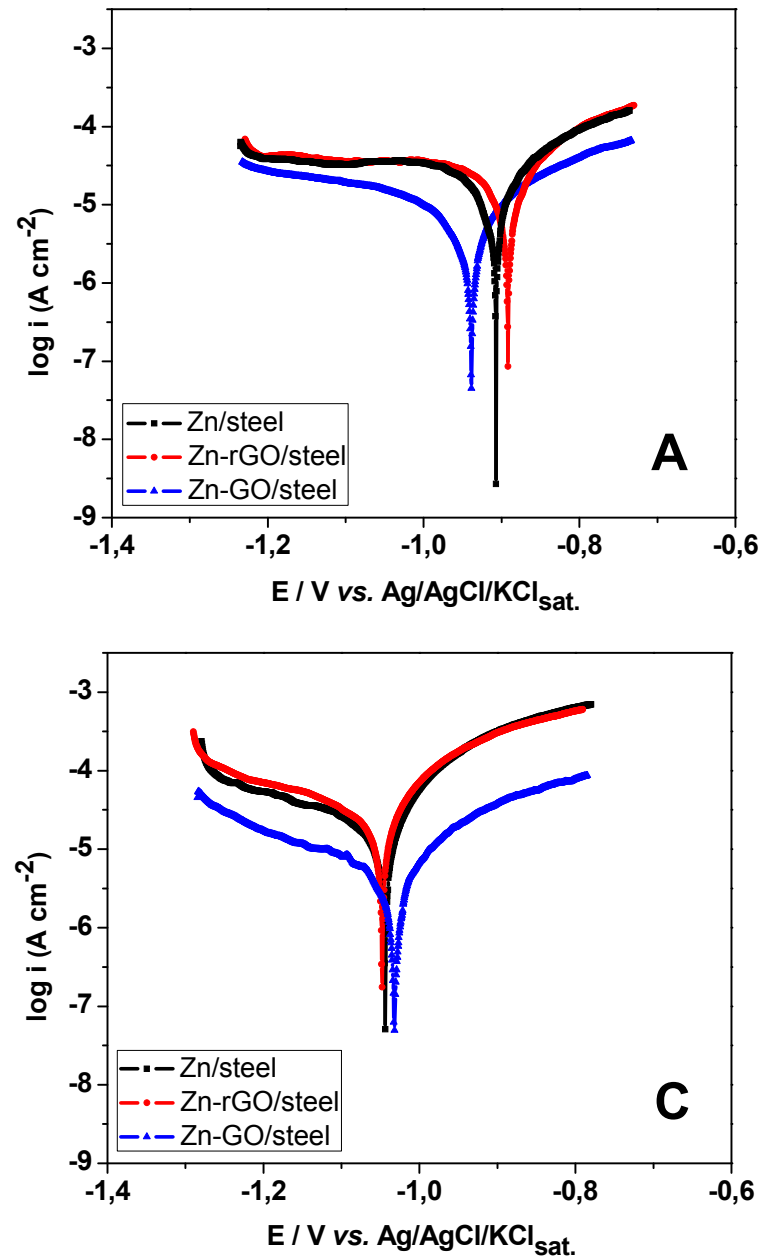

barrier that impedes the diffusion of dissolved oxygen towards the metallic surface and, on the other side, hinders $\mathrm{Zn}$ dissolution.
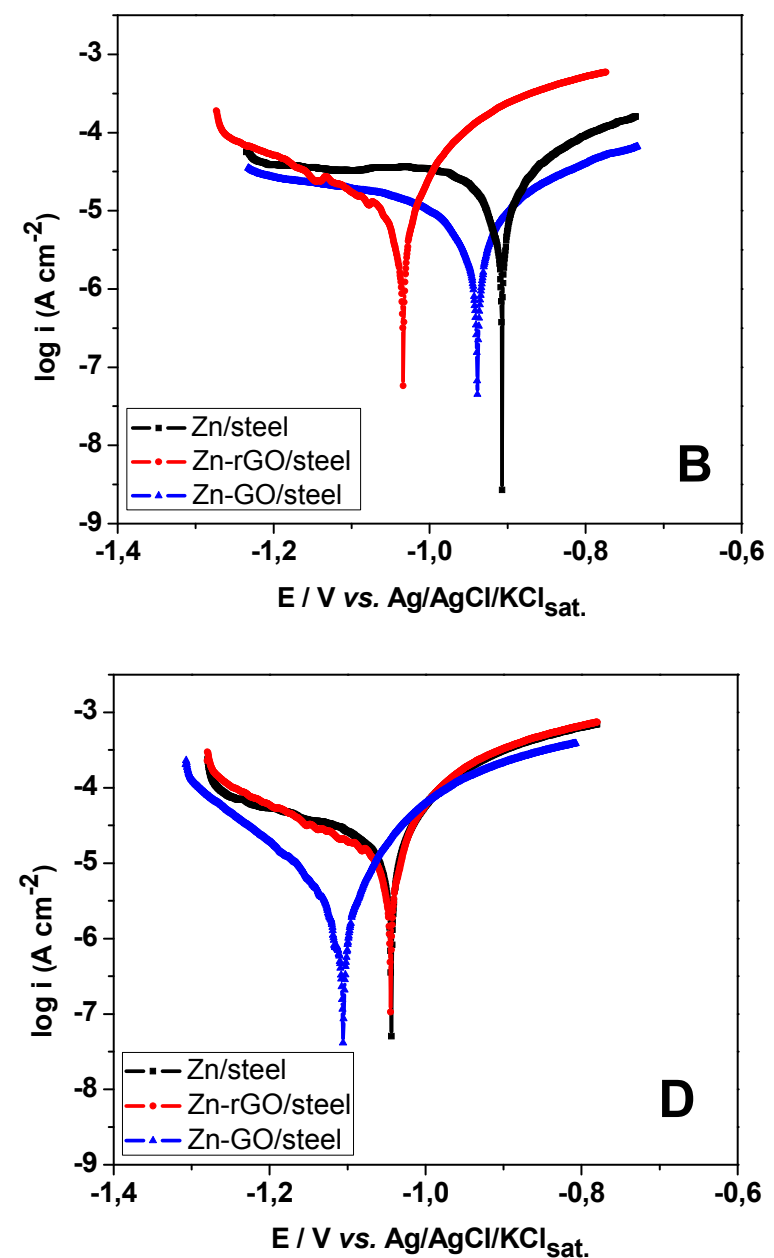

Fig. 3 - Tafel polarization curves recorded for steel coated with $\mathrm{Zn}, \mathrm{Zn}-\mathrm{rGO}$ and $\mathrm{Zn}$-GO composite coatings at $20 \mathrm{~mA} / \mathrm{cm}^{2}$ with $50 \mathrm{mg} / \mathrm{L}$ graphene materials (A), and $100 \mathrm{mg} / \mathrm{L}$ graphene materials (B) and at $40 \mathrm{~mA} / \mathrm{cm}^{2}$ with $50 \mathrm{mg} / \mathrm{L}$ graphene materials (C), and $100 \mathrm{mg} / \mathrm{L}$ graphene materials (D); deposition time, 20 minutes.
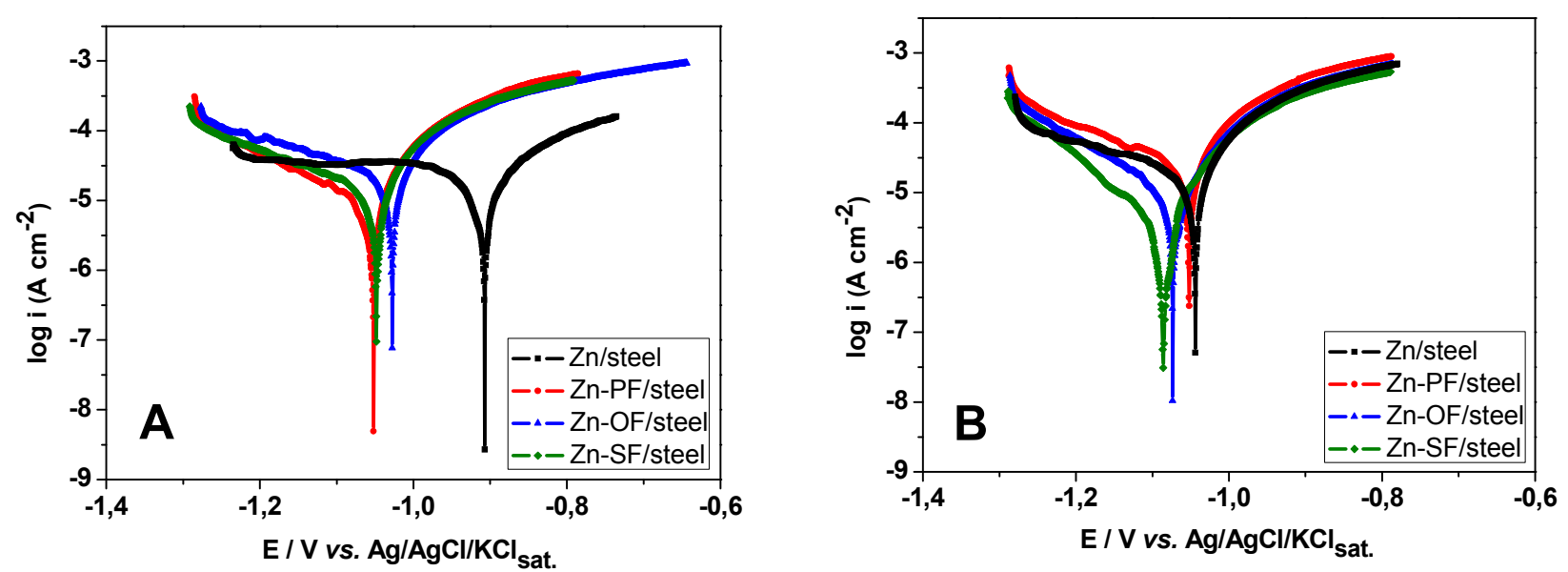

Fig. 4 - Tafel polarization curves recorded for steel covered with Zn-PF, Zn-OF and Zn-SF composite coatings at $20 \mathrm{~mA} / \mathrm{cm}^{2}$ (A) and at $40 \mathrm{~mA} / \mathrm{cm}^{2}$ (B) with $50 \mathrm{mg} / \mathrm{L}$ graphene materials; deposition time, $20 \mathrm{~min}$. 
Table 2

The electrochemical parameters, estimated by extrapolation of the Tafel curves for different zinc-based protective coatings on steel

\begin{tabular}{|c|c|c|c|c|c|}
\hline \multirow{3}{*}{ Sample } & \multirow{3}{*}{$\begin{array}{c}\text { Graphene } \\
\text { concn. } \\
(\mathrm{mg} / \mathrm{L})\end{array}$} & \multicolumn{2}{|c|}{$\begin{array}{c}E_{\text {corr }} \\
\left(\mathrm{mV} \text { vs. } \mathrm{Ag} / \mathrm{AgCl} / \mathrm{KCl}_{\text {sat }}\right)\end{array}$} & \multicolumn{2}{|c|}{$\begin{array}{c}i_{\text {corr }} \\
\left(\mu \mathrm{A} / \mathbf{c m}^{2}\right)\end{array}$} \\
\hline & & \multicolumn{4}{|c|}{ Deposition current density $\left(\mathrm{mA} / \mathrm{cm}^{2}\right)$} \\
\hline & & 20 & 40 & 20 & 40 \\
\hline $\mathrm{Zn} /$ steel & 0 & -906 & -1042 & 21.88 & 21.38 \\
\hline Zn-rGO/steel & & -891 & -1049 & 18.62 & 23.98 \\
\hline Zn-GO/steel & 50 & -937 & -1030 & 7.58 & 6.03 \\
\hline Zn-rGO/steel & & -1034 & -1044 & 12.02 & 11.09 \\
\hline $\mathrm{Zn}-\mathrm{GO} /$ steel & 100 & -941 & -1106 & 7.24 & 2.63 \\
\hline Zn-PF/steel & & -1053 & -1052 & 16.98 & 17.21 \\
\hline Zn-OF/steel & 50 & -1032 & -1076 & 21.03 & 13.18 \\
\hline Zn-SF/steel & & -1050 & -1088 & 19.05 & 6.62 \\
\hline
\end{tabular}

It can be seen that in most cases, the beneficial effect of GO fractions is more evident when 100 $\mathrm{mg} / \mathrm{L}$ are used. This is in agreement with the observation that, in the case of composite coatings obtained electrolytically, the concentration of nanoparticles in the electrolyte controls their incorporation degree and is an important experimental parameter. ${ }^{9,7}$ The increase of electrodeposition current density from $20 \mathrm{~mA} / \mathrm{cm}^{2}$ to $40 \mathrm{~mA} / \mathrm{cm}^{2}$ does not change significantly the corrosion current density values recorded at the composite samples.

Irrespective to the current density used, a very similar behavior of the deposits containing the three different fractions PF, OF and SF is observed from Figure 4 suggesting same incorporation mechanism of these fractions in the zinc deposit. In the same time, it should be mentioned that their effect on the corrosion behavior of samples is not as important as that of electrochemically reduced GO during zinc deposition. This could be due to the lower incorporation degree of the fractions in the composite deposits, affecting their microstructure and consequently, their corrosion resistance. A dependence of the incorporation fraction on the nanoparticles characteristics was already reported for other metallic composites such as $\mathrm{Ni}-\mathrm{TiO}_{2}{ }^{7,31} \mathrm{Zn}-\mathrm{TiO}_{2}{ }^{9}$ etc. These characteristics certainly play an essential role in their incorporation mechanism and consequently, may influence the corrosion behavior of the resulting coatings.

The small differences between the corrosion current density values noticed for the three GO fractions could be explained based on some particularities of these fractions, such as the unreacted free functional groups (associated with the oxidation degree). It was previously shown ${ }^{30}$ that the ratio of the peak intensities of carbon to oxygen $(\mathrm{C} / \mathrm{O}$ ratios $)$ in XPS spectra of the graphene fractions were 1.43 for SF, 2.12 for OF and 2.20 for $\mathrm{PF}$ suggesting a lower oxidation degree of $\mathrm{PF}$ and $\mathrm{OF}$, as compared with the SF fraction. This could lead to a lower incorporation degree of $\mathrm{PF}$ and $\mathrm{OF}$ fractions during electrodeposition, which contributes to the slightly lower corrosion resistance of the resulting deposits. Thus, it is confirmed once again that the preparation method and the reduction of GO is a key topic, and different reduction processes result in different properties that in turn affect the final performance of materials or devices containing $\mathrm{rGO}^{32}$

\section{Electrochemical impedance spectroscopy}

In order to get a deeper insight into the corrosion behavior of the newly prepared coatings, electrochemical impedance measurements were carried out at the open circuit potential immersed in a $0.2 \mathrm{~g} / \mathrm{L} \mathrm{Na} \mathrm{SO}_{4}+0.2 \mathrm{~g} / \mathrm{L} \mathrm{NaHCO}_{3}$ corrosive solution adjusted to $\mathrm{pH}=5$ with $\mathrm{H}_{2} \mathrm{SO}_{4}$. In Figure 5 are presented the Nyquist diagrams for the most resistant coating ( $\mathrm{Zn}-\mathrm{GO} /$ steel) and for the $\mathrm{Zn} /$ steel coating, as a reference after 36 hours of immersion in the corrosive solution.

To simulate the electrode/solution interface, a 2RQ parallel circuit equivalent circuit previously proposed by Kumar et al. ${ }^{29}$ was used (Figure 6). The equivalent circuit is based on the existence of 
a dielectric coating $\left(Q_{\text {coat }}\right)$ reinforced by ionic conduction through its pores $\left(R_{\text {coat }}\right)$. The parameter $R_{\mathrm{e}}$ is correlated with the solution resistance, while the $R_{\mathrm{ct}}-Q_{\mathrm{dl}}$ parameters correspond to the charge transfer resistance at the interface coupled with the double layer pseudo-capacitance. The elements, $C_{\text {coat }}$ and $C_{\mathrm{dl}}$, represented in the circuit as capacitors, were fitted as constant phase elements (CPEs) described by the terms $Q$ and $n$. The impedance of the CPE is given by the following equation: ${ }^{33}$

$$
\mathrm{Q}=\mathrm{Z}_{\mathrm{CPE}(\omega)}=\left[C(j \omega)^{\mathrm{n}}\right]^{-1}
$$

where $j$ is an imaginary number and $\omega$ is the angular frequency in $\mathrm{rad} / \mathrm{s}$. The values of $n$ are associated with the non-uniform distribution of current as a result of roughness and surface defects.

It is worth mentioning that by using graphene oxide nanoparticles in the plating baths different kinetic parameters were obtained as compared to pure $\mathrm{Zn}$ coatings (Table 3 ).

The time evolution of the impedance diagrams recorded for $\mathrm{Zn}-\mathrm{GO} /$ steel deposits, showed an increase of the impedance modulus in the first 36 $\mathrm{h}$, reaching a relatively good and constant corrosion resistance value of the composite layer (results not shown). Moreover, after $36 \mathrm{~h}$ the $R_{\mathrm{p}}$ value for the composite layer overcomes the value noticed for the pure $\mathrm{Zn}$ layer (Figure 5). A further constant increase of $R_{\mathrm{p}}$ in the case of $\mathrm{Zn}-\mathrm{GO} / \mathrm{steel}$ coatings is noticed (Table 3 ), reflecting a progressive hindering of the corrosion reaction. $C_{\mathrm{dl}}$ is significantly decreased for the composite layer, suggesting also a diminished activity of the surface towards corrosion.

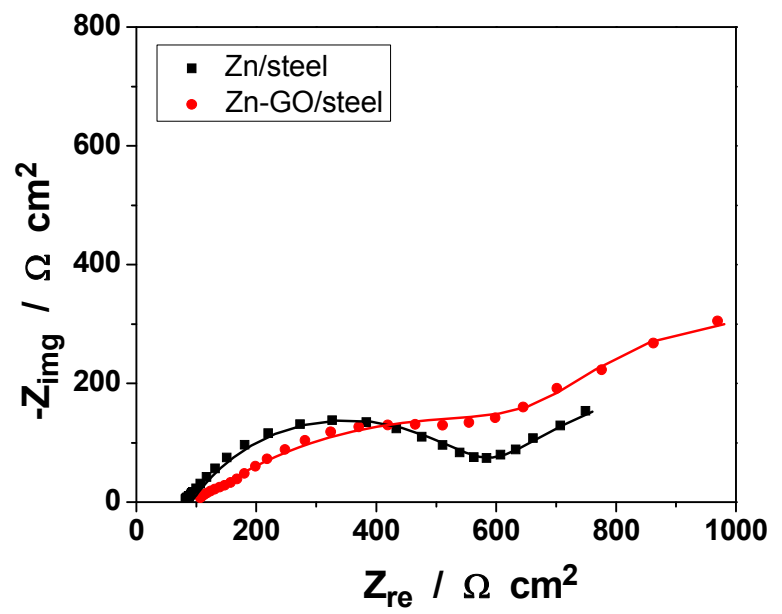

Fig. 5 - Electrochemical Impedance Spectroscopy (EIS) diagrams of steel coated with $\mathrm{Zn}$ and for $\mathrm{Zn}-\mathrm{GO} / \mathrm{steel}$ after $36 \mathrm{~h}$ immersed in $0.2 \mathrm{~g} / \mathrm{L} \mathrm{Na}_{2} \mathrm{SO}_{4}+0.2 \mathrm{~g} / \mathrm{L} \mathrm{NaHCO}$ $(\mathrm{pH}=5)$. Lines represent the calculated data. Electrodeposition parameters: $\mathrm{i}=40 \mathrm{~mA} / \mathrm{cm}^{2}$; $\mathrm{GO}$ concentration in the electrolyte, $100 \mathrm{mg} / \mathrm{L}$; deposition time, 20 minutes.

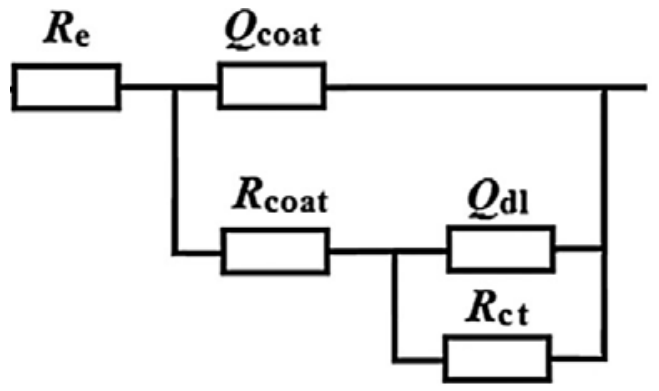

Fig. 6 - Equivalent circuit used for interpreting the experimental impedance data.

Table 3

Values of fitted parameters of the equivalent circuit for time evolution of the impedance for steel coated with $\mathrm{Zn}$ and $\mathrm{Zn}$-GO immersed in $0.2 \mathrm{~g} / \mathrm{L} \mathrm{Na}_{2} \mathrm{SO}_{4}+0.2 \mathrm{~g} / \mathrm{L} \mathrm{NaHCO}_{3}(\mathrm{pH}=5)$ after $1 \mathrm{~h}$ of immersion. Electrodeposition parameters: $\mathrm{i}=40 \mathrm{~mA} / \mathrm{cm}^{2} ; \mathrm{GO}$ concentration in the electrolyte, $100 \mathrm{mg} / \mathrm{L}$; deposition time, 20 minutes

\begin{tabular}{|c|c|c|c|c|c|c|c|c|c|c|}
\hline $\begin{array}{c}\text { Time } \\
\text { evolution } \\
\text { (h) }\end{array}$ & $\begin{array}{c}R_{\mathrm{e}} \\
\left(\Omega \mathrm{cm}^{2}\right)\end{array}$ & $\begin{array}{c}R_{\text {coat }} \\
\left(\Omega \mathrm{cm}^{2}\right)\end{array}$ & $\underset{\left(m \Omega^{-1} \mathbf{s}^{\mathbf{n}} \mathbf{c m}^{-2}\right)}{Q_{\text {coat }}}$ & $\mathrm{n}_{1}$ & $\begin{array}{c}C_{\text {coat }} \\
\left(\mathrm{mF} \mathrm{cm}^{-2}\right)\end{array}$ & $\begin{array}{c}R_{\mathrm{ct}} \\
\left(\Omega \mathrm{cm}^{2}\right)\end{array}$ & $\underset{\left(\Omega^{-1} \mathbf{s}^{\mathrm{n}} \mathbf{c m}^{-2}\right)}{Q_{\mathrm{l}}}$ & $\mathbf{n}_{2}$ & $\begin{array}{c}C_{\mathrm{dl}} \\
\left(\mathrm{F} \mathrm{cm}^{-2}\right)\end{array}$ & $\begin{array}{c}* R_{\mathrm{p}} \\
\left(\Omega \mathbf{c m}^{2}\right)\end{array}$ \\
\hline \multicolumn{11}{|c|}{ Zn/steel } \\
\hline 1 & 90 & 235 & 0.16 & 0.608 & 0.018 & 326 & 0.040 & 0.608 & 0.207 & 561 \\
\hline 36 & 92 & 502 & 0.18 & 0.632 & 0.043 & 742 & 0.018 & 0.592 & 0.103 & 1244 \\
\hline 48 & 89 & 610 & 0.16 & 0.647 & 0.043 & 813 & 0.011 & 0.579 & 0.049 & 1423 \\
\hline 60 & 85 & 589 & 0.15 & 0.651 & 0.042 & 722 & 0.010 & 0.588 & 0.043 & 1311 \\
\hline \multicolumn{11}{|c|}{ Zn-GO/steel } \\
\hline 1 & 105 & 158 & 0.91 & 0.437 & 0.074 & 414 & 0.048 & 0.706 & 0.160 & 572 \\
\hline 36 & 112 & 812 & 0.77 & 0.407 & 0.384 & 659 & 0.018 & 0.898 & 0.023 & 1471 \\
\hline 48 & 104 & 808 & 0.74 & 0.414 & 0.363 & 685 & 0.017 & 0.914 & 0.022 & 1493 \\
\hline 60 & 103 & 796 & 0.75 & 0.411 & 0.364 & 734 & 0.015 & 0.872 & 0.021 & 1530 \\
\hline
\end{tabular}




\section{EXPERIMENTAL}

\section{Materials/Synthesis}

The various graphene oxides used for the electrodeposition of zinc composite coatings and their preparation modes are presented in Table 4.

The preparation and characterization of IF, SF, OF and $\mathrm{PF}$ was presented elsewhere. ${ }^{30}$ Briefly, a mixture of $\mathrm{H}_{2} \mathrm{SO}_{4}(270$ $\mathrm{mL}, 95-97 \%$, Reactivul Bucureşti), $\mathrm{H}_{3} \mathrm{PO}_{4}(30 \mathrm{~mL}, 85 \%$, Merck), graphite ( $2.7 \mathrm{~g}$, purum powder $<0.1 \mathrm{~mm}$, Fluka) and $\mathrm{KMnO}_{4}$ (12 g, Merck, 99\%) was realized and held for $2 \mathrm{~h}$ in ice bath and 4 days at room temperature. After that, $\mathrm{H}_{2} \mathrm{O}_{2}$ (200 mL, 3\%, Riedel-de Haën) was added to the previously obtained mixture placed in ice bath for $1 \mathrm{~h}$ and subsequently the suspension was centrifuged $(5000 \mathrm{rpm}, 15 \mathrm{~min})-$ dispersed -sonicated (15 min) in $\mathrm{H}_{2} \mathrm{O}$ (200 $\mathrm{mL}$; one time), $\mathrm{HCl}$ (100 mL, 37\%, Sigma-Aldrich; two times) and ethanol (100 $\mathrm{mL}, 37 \%$, Reactivul București; two times). The obtained wet solid was dispersed in a $50 \%$ aqueous ethanol solution and sonicated again for $15 \mathrm{~min}$. After 7 days, $90 \%$ of upper part of the GO suspension was harvested as initial fraction (IF) from which three distinct GO fractions - supernatant (SF), oil-like (OF) and paste-like (PF) (see Table 4) - were obtained by centrifugation (6000 rpm, $2 \mathrm{~h}$ ).

\section{Electrodeposition of zinc-graphene composite coatings}

The electrodeposition experiments were performed in a classical cell (volume of $100 \mathrm{~mL}$ ) with a three electrode arrangement: a steel disc impressed in a Teflon cylindrical holder was used as the working electrode $\left(\mathrm{A}=0.5024 \mathrm{~cm}^{2}\right)$, a $\mathrm{Pt}$ wire was used as the counter electrode and a commercial ALS RE-1B $\mathrm{Ag} / \mathrm{AgCl} / \mathrm{KCl}_{\text {sat }}$ was used as the reference electrode. The reference electrode was separated from the electrolyte bulk via a Luggin capillary filled with the investigated electrolyte. To prepare the working electrode for investigation, the disc shaped steel surface was polished on emery paper by different granulation (from 600 to 3000) and finally on felt with $\mathrm{Al}_{2} \mathrm{O}_{3}$ (alumina) to clean the metallic dust.

Before electrodeposition, the working electrode was ultrasonicated for 2 minutes in ethanol, then thoroughly rinsed with ethanol and distilled water in order to remove any remaining impurities from the surface.

The composition of electrolyte used in the electrodeposition process is presented in Table 5. The plating time used for electrodeposition was 20 minutes and two current densities were employed: $20 \mathrm{~mA} / \mathrm{cm}^{2}$ or $40 \mathrm{~mA} / \mathrm{cm}^{2}$. Electrodeposition process was carried out at room temperature and the plating solution was stirred at $200 \mathrm{rpm}$ speed throughout the deposition process.

Table 4

Graphene oxide (GO) types used in the zinc composites electrodeposition process

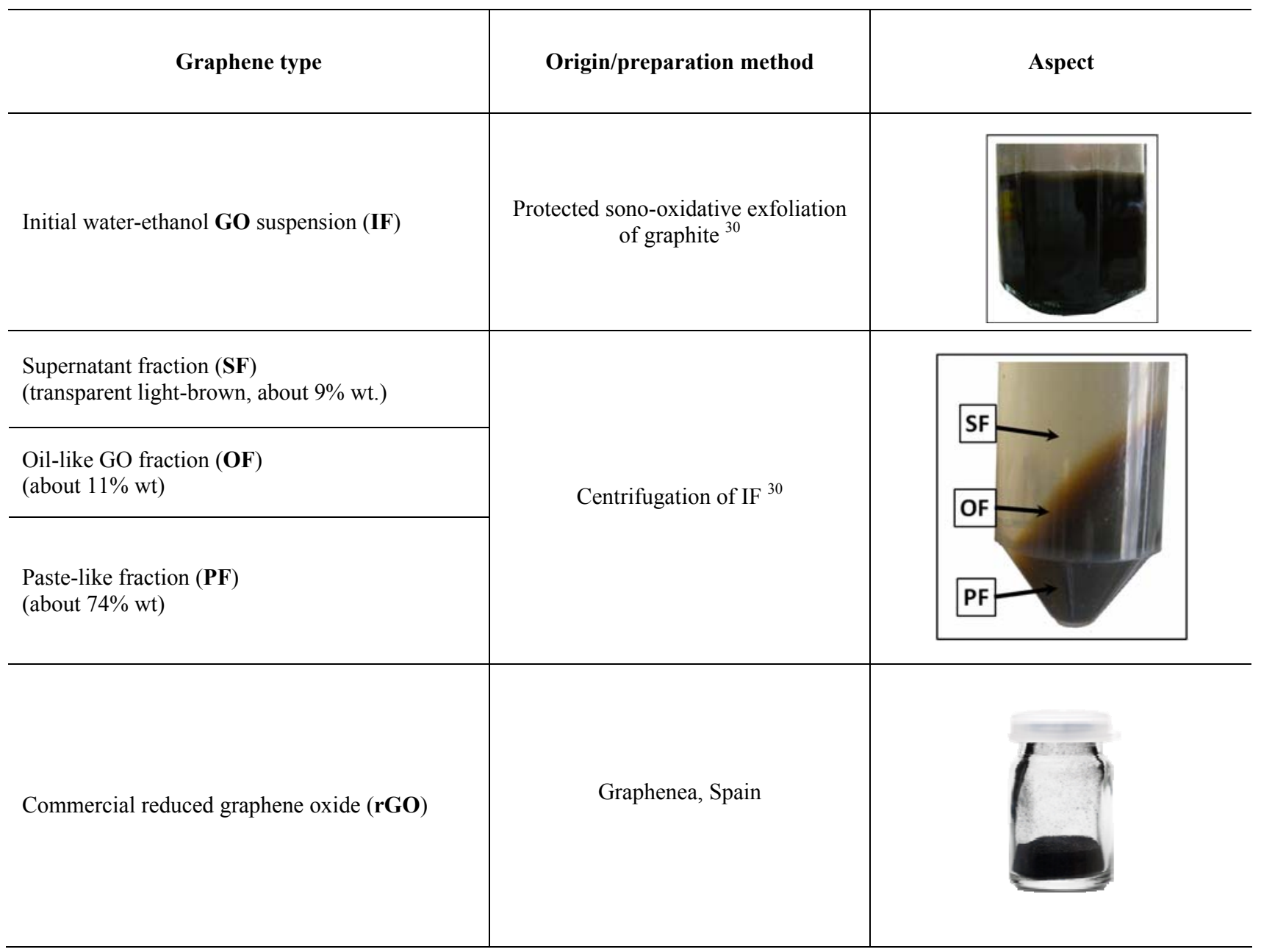


Table 5

Electrolyte composition used in the electrodeposition of composite zinc-graphene coatings

\begin{tabular}{c|c|c}
\hline Electrolyte & Composition & pH \\
\hline \multirow{2}{*}{ Synthetic electrolyte $^{29}$} & $320.4 \mathrm{~g} / \mathrm{L} \mathrm{ZnSO}_{4} 7 \mathrm{H}_{2} \mathrm{O}$ & \\
& $30 \mathrm{~g} / \mathrm{L} \mathrm{Na}_{2} \mathrm{SO}_{4}$ & 5.6 \\
& $10 \mathrm{~g} / \mathrm{L} \mathrm{NaCl}$ & \\
\hline
\end{tabular}

$\mathrm{ZnSO}_{4} \cdot 7 \mathrm{H}_{2} \mathrm{O}, \quad \mathrm{NaHCO}_{3}, \quad \mathrm{Na}_{2} \mathrm{SO}_{4}, \quad \mathrm{NaCl}$ and $\mathrm{CTAB}$ (cetyltrimethylammonium bromide) were obtained from Merck, Germany. The obtained Zn-graphene composites, in which IF of GO and commercial rGO were used, were termed as $\mathrm{Zn}-\mathrm{GO}$ and $\mathrm{Zn}-\mathrm{rGO}$, respectively. $\mathrm{Zn}-\mathrm{PF}, \mathrm{Zn}-\mathrm{OF}$ and $\mathrm{Zn}-$ SF were termed the composites obtained by using the three GO fractions resulted by IF centrifugation (see Table 4). The concentrations of graphene materials in the electrolytes during electrodeposition were 50 and $100 \mathrm{mg} / \mathrm{L}$, respectively.

\section{Corrosion tests}

The corrosion tests were carried out in simulated acid rain $\left(0.2 \mathrm{~g} / \mathrm{L} \mathrm{Na}_{2} \mathrm{SO}_{4}+0.2 \mathrm{~g} / \mathrm{L} \mathrm{NaHCO}_{3}\right)$ adjusted with $\mathrm{H}_{2} \mathrm{SO}_{4} 1 \mathrm{~N}$ to $\mathrm{pH}=5$. Open circuit potential $\left(\mathrm{E}_{\mathrm{oc}}\right)$ measurements were performed as a function of time. Anodic and cathodic polarization curves were recorded in a potential range of $\mathrm{E}=$ $\mathrm{E}_{\text {corr }} \pm 250 \mathrm{mV}$, with a scan rate of $0.166 \mathrm{mV} / \mathrm{s}$. All electrochemical tests were performed at room temperature with computer-controlled potentiostat/galvanostat PARSTAT (Princeton Applied Research) Model 2273, compatible with PowerSuite software. Electrochemical impedance spectroscopy (EIS) measurements were carried out at $\mathrm{E}_{\mathrm{oc}}$, in the frequency range of $100 \mathrm{kHz}-10 \mathrm{mHz}$ at 10 points per decade with an AC voltage amplitude of $\pm 10 \mathrm{mV}$. Electrochemical impedance data were fitted using ZSimpWin 3.21 software.

\section{Morpho-structural investigations}

X-Ray Diffraction measurements (XRD) were carried out at room temperature on a Bruker D8 Advance powder diffractometer using $\mathrm{Cu} \mathrm{K} \alpha_{1}$ radiation $(\lambda=0.154056 \mathrm{~nm})$. The $\theta-2 \theta$ Bragg-Brentano configuration geometry and incidentbeam Ge (111) monochromator were used to investigate the structural properties of the samples. The measurements were performed in the $10-80^{\circ}$ range in steps of $0.01^{\circ}$.

The Scanning Electron Microscopy (SEM) was performed using an Ultra High Resolution (UHR) SEM Hitachi 8230 system operated in high vacuum conditions. The instrument capabilities allow particular scanning options in order to show the distribution of components in relation to their chemical composition and topography of the studied surface. High resolution SEM images acquired at low landing voltage can be assessed without destruction of the samples. The SEM accelerating voltage was $15 \mathrm{kV}$ in a vacuum of $10^{-5} \mathrm{mbar}$ and secondary electrons images combined with Energy Dispersion Spectroscopy (EDS) analysis were used to investigate the morphological properties.

\section{CONCLUSIONS}

Graphene material incorporation in zinc deposits can be successfully done by simultaneous reduction of $\mathrm{GO}$ and $\mathrm{Zn}^{2+}$ ions during electrodeposition.

Electrochemical measurements (polarization measurements and electrochemical impedance spectroscopy) carried out in a $0.2 \mathrm{~g} / \mathrm{L} \mathrm{Na}_{2} \mathrm{SO}_{4}+0.2$ $\mathrm{g} / \mathrm{L} \mathrm{NaHCO}_{3}$ corrosive solution adjusted to $\mathrm{pH}=5$ with $\mathrm{H}_{2} \mathrm{SO}_{4}$ demonstrated that the incorporation of graphene material in zinc enhanced the corrosion resistance of the resulting composite coatings when compared to pure zinc coating. The inhibition efficiencies determined from the values of current densities by Tafel method are higher than those determined by EIS, probably due to the longer duration of the later experiments.

Even if no spectacular differences were observed between the deposits prepared with different GO types, it can be concluded that the degree of inhibition depends on graphene incorporation degree, which depends on the GO type and its preparation mode. Understanding the electrodeposition mechanism, as well as corroborating the results of the corrosion tests with the preparation methods of GOs, could lead to better corrosion resistance performances of galvanized steel.

Future research should mainly focus on a much deeper understanding of the reduction mechanism of GO in order to obtain a non-defective graphene material, able to improve significantly the mechanical and anti-corrosive properties of composite coatings.

Acknowledgements. This work was supported from funds of TeMATIC-Art, Cod proiect: P_40_374, No. 34375/09.08.2017”, Project co-financed by FEDR through Competitiveness Operational Programme 2014 - 2020. Funding contract: 14/01.09.2016, MySMIS: 105765. The authors would like to thank Dr. Lucian Barbu-Tudoran for SEM measurements obtained through the infrastructure from the Research Center and Advanced Technologies for Alternative Energies-CETATEA.

\section{REFERENCES}

1. B. M. Praveen, T. V. Venkatesha, Y. Arthoba Naik, K. Prashantha, Surf. Coat. Tech. 2007, 201, 5836-5842.

2. C. Gabrielli, M. Keddam, F. Minouflet-Laurent, K. Ogle, H. Perrot, Electrochim. Acta 2003, 48, 1483-1490. 
3. S. F. L. Mertens, E. Temmerman, Corros. Sci. 2001, 43, 301-316.

4. E. Frackowiak, J. M. Skowronski, J. Power Sources 1998, 73, 175-181.

5. J. I. Martins, T. C. Reis, M. Bazzaoui, E. A. Bazzaoui, L. Martins, Corros. Sci. 2004, 46, 2361-2381.

6. A. Hovestad, L. J. J. Janssen, J. Appl. Electrochem. 1995, 25, 519-527.

7. C. T. J. Low, R. G. A. Wills, F. C. Walsh, Surf. Coat. Tech. 2006, 201, 371-383.

8. A. Bund, D. Thiemig, J. Appl. Electrochem. 2007, 37, 345-351.

9. A. Vlasa, S. Varvara, A. Pop, C. Bulea, L. M. Muresan, $J$ Appl. Electrochem. 2010, 40, 1519-1527.

10. A. Gomes, M. I. Da Silva Pereira, M. H. Mendonça, F. M. Costa, J. Solid State Electrochem. 2005, 9, 190-196.

11. T. Deguchi, K. Imai, H. Matsui, M. Iwasaki, H. Tada, S. Ito, J. Mater. Sci. 2001, 36, 4723-4729.

12. B. M. Praveen, T. V. Venkatesha, Appl. Surf. Sci. 2008, 254, 2418-2424.

13. K. Kondo, A. Ohgishi, Z. Tanaka, J. Electrochem. Soc. 2000, 147, 2611-2613.

14. T. J. Tuaweri, G. D. Wilcox, Surf. Coat. Tech. 2006, 200, 5921-5930.

15. D. Mukherjee, N. Palaniswamy, S. Guruviah, E. Belthowska, P. Barbara, B. Electrochem. 1990, 6, 380381.

16. S. Oue, H. Nakano, S. Kobayashi, T. Akiyama, H. Fukushima, K. Okumura, J. Surf. Finish Soc. Japan 2002, 53, 920-925.

17. P. I. Nemes, M. Lekka, L. Fedrizzi, L. M. Muresan, Surf. Coat. Tech. 2014, 252, 102-107.
18. P. I. Nemes, M. Zaharescu, L. M. Muresan, J. Solid State Electrochem. 2013, 17, 511-518.

19. P. I. Nemes, N. Cotolan, L. M. Muresan, Studia UBB Chemia, LVIII 2013, 1, 81-91.

20. W. Chengfu, Y. Meifang, T. Jie, Compos. Struct. 1987, 4, 98-104.

21. H. Wang, X. Yuan, G. Zeng, Y. Wu, Y. Liua, Q. Jiang S. $\mathrm{Gu}$, Adv. Colloid Interface 2015, 221, 41-59.

22. Y. Shao, J. Wang, H. Wu, J. Liu, I. A. Aksay, Y. Lin, Electroanalysis 2010, 22, 1027-1036.

23. C. Qiu, D. Liu, K. Jin, L. Fang, G. Xie, J. Robertson, Mater. Chem. Phys. 2017, 198, 90-98.

24. A. M. A. Al-Sammarraie, M. H. Raheema, Int. J. Corros. 2017, 1-8. https://doi.org/10.1155/2017/6939354

25. A. U. Chaudhry, V. Mittal, B. Mishra, Mater. Chem. Phys. 2015, 163, 130-137.

26. C. Liu, F. Su, J. Liang, Appl. Surf. Sci. 2015, 351, 889-896.

27. Y. Raghupathy, A. Kamboj, M. Y. Rekha, N. P. Narasimha Rao, C. Srivastava, Thin Solid Films 2017, 636, 107-115.

28. Z. Ren, N. Meng, K. Shehzad, Y. Xu, S. Qu, B. Yu, J. K. Luo, Nanotechnology 2015, 26, 1-8.

29. M. K. Punith Kumar, M. P. Singh, C. Srivastava, RSC Adv. 2015, 5, 25603-25608.

30. L. C. Cotet, K. Magyari, M. Todea, M. C. Dudescu, V. Danciu, L. Baia, J. Mater. Chem. A 2017, 5, 2132-2142.

31. J. Li, Y. Sun, X. Sun, J. Qiao, Surf. Coat. Tech. 2005, 192, 331-335.

32. S. Pei, H.-M. Cheng, CARBON 2012, 50, 3210-3228.

33. Q. Ni, D. W. Kirk, S. J. Thorpe, "Electrochemical Engineering for the $21^{\text {st }}$ Century", ECS Transactions, USA 2010 p. 55-72. 
